\title{
A vigilância genômica do SARS-CoV-2 no Brasil na resposta à pandemia
} \section{da COVID-19}

\section{Ao Editor,}

Diariamente, milhares de variantes do SARS-CoV-2 surgem no mundo (1), evidenciando o desafio de reforçar a capacidade de detecção oportuna com ampliação e fortalecimento da vigilância epidemiológica, vigilância laboratorial e comunicação rápida, com desenvolvimento de pesquisas em saúde que possam apoiar as medidas de prevenção e controle da pandemia da COVID-19. Ainda que não se conheçam todas as implicações das novas variantes da COVID-19 para o controle da doença, algumas mutações ou combinações podem fornecer ao vírus uma vantagem seletiva, que contribui para aumentar a transmissibilidade ou a capacidade de evadir a resposta imune do hospedeiro.

No Brasil, até 10 de abril de 2021, foram registrados e confirmados 13445006 casos e 361334 óbitos por COVID-19, com incidência acumulada de 6397,9 por 100 mil habitantes e mortalidade de 157,2 por 100 mil habitantes. De acordo com a Organização Mundial da Saúde (OMS), o Brasil é o segundo país com maior número de casos e óbitos por COVID-19 no mundo (2). Entretanto, além da alta incidência e mortalidade pela doença encontradas no Brasil, o Sistema Único de Saúde (SUS) está sendo desafiado pela circulação de variantes de atenção do SARS-CoV-2 nos estados.

No cenário mundial, existem três variantes de atenção para SARS-CoV-2 (3): do Reino Unido (B.1.1.7), com circulação em 111 países; da África do Sul (B.1.351), com circulação em 70 países; e do Brasil (P.1.), com circulação em 36 países. No Brasil, no período compreendido pelas semanas epidemiológicas 1 até 14 de 2021 (ou seja, de 3 de janeiro de 2021 até 10 de abril de 2021), a vigilância genômica identificou essas três variantes de atenção. Quanto à P.1, variante de maior circulação no Brasil, detectada pelas autoridades em 9 de janeiro de 2021, 1690 amostras foram registradas em 24 unidades federadas nas cinco regiões do país, sendo 44,6\% originárias da região Norte. Com relação à B.1.1.7, foi detectada pelas autoridades brasileiras em 2 de janeiro de 2021 e, até o momento, foram identificadas 63 amostras distribuídas em 10 unidades federadas e quatro regiões (Nordeste, Sudeste, Sul e Centro Oeste), porém com concentração no Sudeste (63,5\%). Quanto à B.1.351, apenas um caso foi detectado no país, em 7 de abril de 2021, em São Paulo, região Sudeste.

Os estudos sobre a variante de atenção P.1. ainda são muito limitados, havendo poucas evidências disponíveis para determinar uma mudança na transmissibilidade ou gravidade da doença (4). No entanto, é plausível o aumento da transmissibilidade, tendo em vista a presença de alteração de aminoácidos N501Y nas três variantes de atenção $(5,6)$. Com relação à B.1.1.7, pesquisas do Reino Unido estimam ser até 71\% mais transmissível do que a forma anteriormente circulante do vírus, com possibilidade de carga viral mais alta (6). No rastreamento de contatos, a taxa de ataque secundário pode ser maior, de $15,1 \%$ versus $9,8 \%$ em outras variantes (6). Estudos afirmam que a variante de atenção B.1.351 pode apresentar maior potencial de transmissibilidade, cerca de 50\%, em comparação com as variantes pré-existentes, além de ser amplamente resistente a anticorpos neutralizantes, podendo gerar risco significativo de reinfecção (6).

Nesse cenário, muitas perguntas precisam ser respondidas de forma oportuna, como: existem diferenças na doença provocada pelas variantes de atenção? Como as variantes podem afetar a assistência, as práticas terapêuticas, a resposta às vacinas e os testes disponíveis? Em busca de respostas, desde 8 de fevereiro de 2021 o Ministério da Saúde do Brasil está implementando um plano nacional de fortalecimento e ampliação da vigilância genômica para SARS-CoV-2. Entre os objetivos propostos estão: identificar estratégias de vigilância genômica; orientar quanto aos critérios para sequenciamento de amostras; padronizar o envio dos resultados das pesquisas genômicas; reforçar a comunicação imediata e oportuna; e analisar os resultados das pesquisas genômicas em parceria com a vigilância epidemiológica. Em um prazo de 14 dias, a rede de vigilância genômica passou de 10 amostras mensais por estado para três mil amostras a cada 4 semanas epidemiológicas. Acreditamos que o fortalecimento da rede mundial de vigilância genômica seja um dos caminhos para subsidiar as medidas de controle da pandemia da COVID-19 em todo o mundo, tornando possível o enfrentamento do desafio das variações do SARS-CoV-2 no SUS e no Brasil.

\section{Conflitos de interesse. Nada declarado pelos autores.}

Declaração. As opiniões expressas no manuscrito são de responsabilidade exclusiva dos autores e não refletem necessariamente a opinião ou política da RPSP/PAJPH ou da Organização Pan-Americana da Saúde (OPAS).

\section{Janaína Sallas}

Faculdade de Ciências da Saúde, Programa de Pós-Graduação de Ciências da Saúde, Universidade de Brasília, Brasília (DF), Brasil $₫$ Janaína Sallas, janainasallas@gmail.com

\section{Guilherme Almeida Elidio}

Faculdade de Ciências da Saúde, Programa de Pós-Graduação de Ciências da Saúde, Universidade de Brasília, Brasília (DF), Brasil. 


\section{Daniela Buosi Rohlfs}

Ministério da Saúde, Secretaria de Vigilância em Saúde, Brasília, (DF), Brasil.

\section{Arnaldo Correia de Medeiros}

Ministério da Saúde, Secretaria de Vigilância em Saúde, Brasília, (DF), Brasil.

\section{Dirce Bellezi Guilhem}

Faculdade de Ciências da Saúde, Programa de Pós-Graduação de Ciências da Saúde, Universidade de Brasília, Brasília (DF), Brasil.

Como citar Sallas J, Elídio GA, Rohlfs DB, Medeiros AC, Guilhem DB. A vigilância genômica do SARS-CoV-2 no Brasil na resposta à pandemia da COVID-19. Rev Panam Salud Publica. 2021:45;e75. https://doi.org/10.26633/RPSP.2021.75

\section{REFERÊNCIAS}

1. Burki T. Understanding variants of SARS-CoV-2. Lancet (London, England). 2021;397(10273):462. https://doi.org/10.1016/S0140-6736 (21)00298-1

2. World Health Organization (WHO). COVID-19 weekly epidemiological update 22. Disponível em: https://www.who.int/docs/defaultsource/coronaviruse/situation-reports/weekly_epidemiological_ update_22.pdf Acessado em abril de 2021.

3. World Health Organization (WHO). Weekly epidemiological update on COVID-19 - 30 March. Disponível em:: https://www. who.int/docs/default-source/coronaviruse/situation-reports / weekly_epidemiological_update_22.pdf Acessado em abril de 2021.
4. Martins AF, Zavascki AP, Wink PL, Volpato FCZ, Monteiro FL, Rosset C, et al. Detection of SARS-CoV-2 lineage P.1 in patients from a region with exponentially increasing hospitalization rates in February 2021, Rio Grande do Sul, Southern Brazil. medRxiv. 2021;26(12): 2021.03.09.21253204. https://doi.org/10.1101/2021.03.09.21253204

5. Le Page M. Threats from new variants. New Sci. 2021;249(3316):8-9. http://dx.doi.org/10.1016/S0262-4079(21)00003-8

6. Ministry of Health (New South Wales). Critical Intelligence Unit. SARS-CoV-2 Variants. 2021;(February):1-30. https://aci.health.nsw. gov.au/_data/assets/pdf_file/0010/627409/20210125-EvidenceCheck-SARS-CoV-2-Variants.pdf Acessado em abril de 2021. 